\title{
Targeting the BACE1 Active Site Flap Leads to a Potent Inhibitor That Elicits Robust Brain A $\beta$ Reduction in Rodents
}

\author{
Yong-Jin $\mathrm{Wu},{ }^{*}{ }^{\dagger}$ Jason Guernon, ${ }^{\dagger}$ Fukang Yang, ${ }^{\dagger}$ Lawrence Snyder, ${ }^{\dagger}$ Jianliang Shi, ${ }^{\dagger}$ Andrea Mcclure, ${ }^{\dagger}$
} Ramkumar Rajamani, ${ }^{\dagger}$ Hyunsoo Park, ${ }^{\dagger}$ Alicia Ng, Hal Lewis, ${ }^{\dagger}$ ChiehYing Chang, ${ }^{\dagger}$ Dan Camac, Jeremy H. Toyn, ${ }^{\dagger}$ Michael K. Ahlijanian, ${ }^{\dagger}$ Charles F. Albright, ${ }^{\dagger}$ John E. Macor, ${ }^{\dagger}$ and Lorin A. Thompson ${ }^{\dagger}$

${ }^{\dagger}$ Research and Development, Bristol-Myers Squibb Company, 5 Research Parkway, Wallingford, Connecticut 06492-7660, United States

${ }^{\ddagger}$ Research and Development, Bristol-Myers Squibb Company, PO Box 4000, Princeton, New Jersey 08543-4000, United States

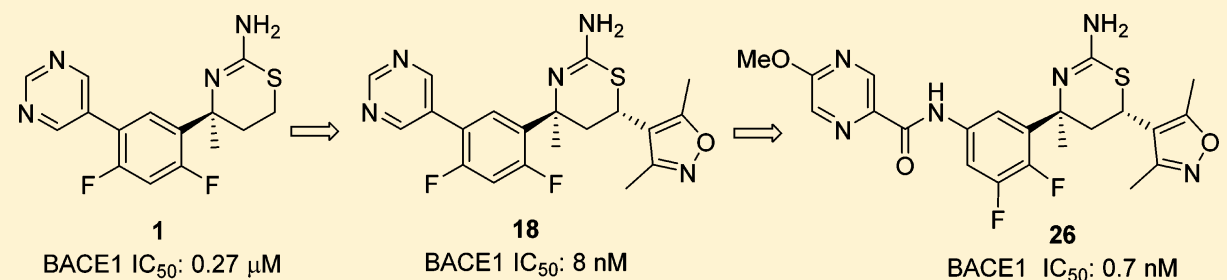

ABSTRACT: By targeting the flap backbone of the BACE1 active site, we discovered 6-dimethylisoxazole-substituted biaryl aminothiazine 18 with 34 -fold improved BACE1 inhibitory activity over the lead compound $\mathbf{1}$. The cocrystal structure of $\mathbf{1 8}$ bound to the active site indicated two hydrogen-bond interactions between the dimethylisoxazole and threonine 72 and glutamine 73 of the flap. Incorporation of the dimethylisoxazole substitution onto the related aminothiazine carboxamide series led to pyrazine-carboxamide 26 as a very potent $\mathrm{BACE} 1$ inhibitor $\left(\mathrm{IC}_{50}<1 \mathrm{nM}\right)$. This compound demonstrated robust brain $\mathrm{A} \beta$ reduction in rat dose-response studies. Thus, compound 26 may be useful in testing the amyloid hypothesis of Alzheimer's disease.

KEYWORDS: BACE1, inhibitor, aminothiazine, A 442 , amyloid hypothesis, Alzheimer's disease

$\mathrm{M}$ ultiple lines of evidence suggest that $\beta$-amyloid $(\mathrm{A} \beta)$ peptide, particularly the longer 42 amino acid form $A \beta 42$, plays a critical role in the progression of Alzheimer's disease (AD) ${ }^{1-3} \mathrm{~A} \beta$ is derived from the $\beta$-amyloid precursor protein (APP) by proteolysis. Human genetic mutations such as the Swedish mutation result in increased $\beta$-secretase processing of $\mathrm{APP}$, elevated $\mathrm{A} \beta$ levels, and ultimately aggressive early onset $\mathrm{AD} .^{4} \mathrm{~A}$ more recent study reported a variant of the APP gene (APPA673T) at a site proximal to the BACE1 proteolytic site that confers protection against $\mathrm{AD} .^{5} \mathrm{~A} 673 \mathrm{~T}$ substitution in APP results in reduced production of $\mathrm{A} \beta$ peptides secreted from heterologously transfected cells, further supporting the hypothesis that increases in $\mathrm{A} \beta$ may underlie the pathology of $\mathrm{AD}$. Cleavage of APP by $\beta$-site APP cleaving enzyme-1 (BACE1) results in shedding of the APP ectodomain, and the remaining membrane bound C-terminal fragment, C99, is further processed by $\gamma$-secretase to produce $\mathrm{A} \beta$. Thus, inhibition of BACE1 to reduce $\mathrm{A} \beta$ production is a promising approach to test the amyloid hypothesis. $^{6-10}$

In 2009, Eli Lilly reported that 1 (LY2811376) (Figure 1), a small molecule biaryl aminothiazine BACE1 inhibitor, demonstrated sustained brain $\mathrm{A} \beta$ reduction in healthy volunteers upon oral administration. ${ }^{11,12}$ The clinical development of this compound was discontinued due to nonclinical, off-targetrelated retinal toxicity. As this compound exhibited only modest

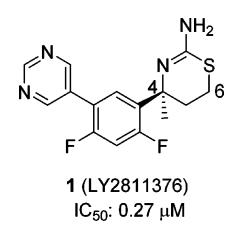

Figure 1. Structure of 1 (LY2811376).

BACE1 inhibitory activity ( $\mathrm{IC}_{50}: 0.27 \mu \mathrm{M}$ from our assay, 0.24 $\mu \mathrm{M}$ from the literature ${ }^{12}$ ), we sought to increase its potency as an avenue to increase the therapeutic window versus the observed toxicity. To our knowledge, no potent biaryl aminothiazine BACE1 inhibitors have been disclosed. We recently developed a novel approach to improve the activity of the biarylaminothiazines, and we then extended this strategy to the related aminothiazine carboxamide series. These efforts culminated in the discovery of a potent BACE1 inhibitor that elicited robust brain $\mathrm{A} \beta$ reduction in rodents. This report describes our progress along these lines.

Received: November 12, 2015

Accepted: January 11, 2016

Published: January 11, 2016 
Examination of the docked conformation of 1 to the BACE1 active site revealed proximity between threonine 72 and glutamine 73 of the flap and the C-6 position of the thiazine ring. We hypothesized that an appropriately selected substituent at C-6 may interact with the flap residues, thus enhancing binding affinity (Figure 2). Unfortunately, the existing synthesis of the 6-

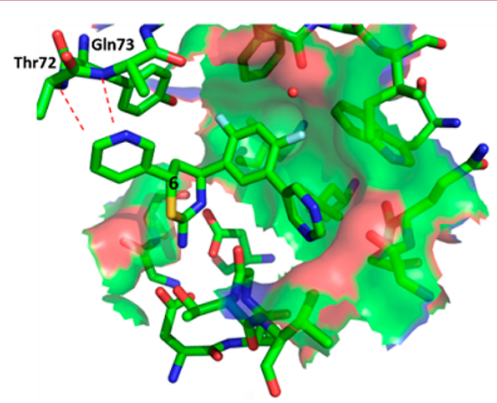

Figure 2. Modeled interaction between the flap backbone of the BACE1 active site and a substituent at the C- 6 of aminothiazine.

substituted aminothiazines 2 was both lengthy and linear, and therefore we desired to develop a more convergent methodology. Retrosynthetically, aminothiazines 2 could be assembled through a $[4+2]$ cycloaddition involving heterodiene 3 and an olefin, and the heterodiene 3 can be visualized from the condensation of an aryl aldehyde or ketone and thiourea (Scheme 1). Indeed, the three-component, one-pot reaction was

Scheme 1. Retrosynthesis of 6-Substituted Aminothiazines

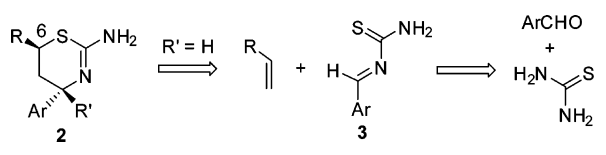

previously described for the synthesis of 4-desmethyl aminothiazines, ${ }^{13}$ and with some minor modifications, we were able to obtain a variety of 4-des-methyl 6-substituted aminothiazines (2, $\left.\mathrm{R}^{\prime}=\mathrm{H}\right)$. However, we were unable to extend this methodology to the synthesis of 4-methyl 6-substituted analogues $\left(2, R^{\prime}=\mathrm{Me}\right)$. At the time this work was carried out (January 2011), the impact of this methyl group was unknown in the literature. ${ }^{14}$ Therefore, our plan was to identify an active 4-desmethyl, 6-substituted aminothiazine using the $[4+2]$ cycloaddition strategy and then to evaluate the impact of the 4-methyl group on potency.

Our work began with the three-component, one-pot reaction of the commercially available 3-(pyrimidin-5-yl)-benzaldehyde (4a) with a variety of substituted styrenes 5 (Scheme 2 ). In general, these reactions proceeded in moderate yields, and the

Scheme 2. Synthesis of 6-Substituted Aminothiazines

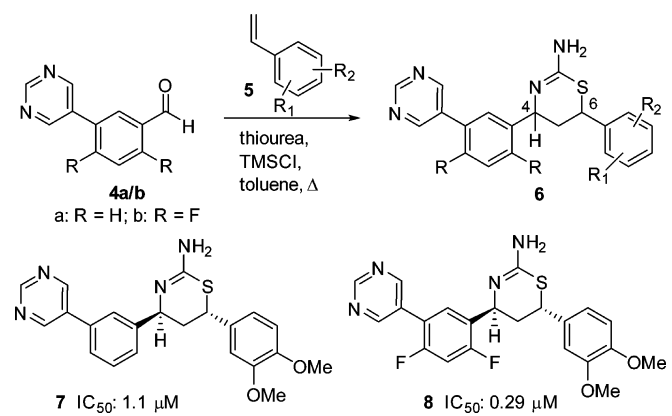

4,6-cis products were predominant over the trans isomers. The minor trans isomers were significantly more active than their corresponding cis counterparts (data not shown). The most active compound from this small library was the $(4 S, 6 S)-6-(3,4-$ dimethoxyphenyl)-substituted aminothiazine $7\left(\mathrm{IC}_{50}: 1.1 \mu \mathrm{M}\right.$, Scheme 2). We then introduced the difluoro substituents onto 7 using 2,4-difluoro-5-(pyrimidin-5-yl)-benzaldehyde (4b, Scheme 2) in the three-component reaction, and the resulting analogue 8 exhibited an approximately 4-fold improved BACE1 inhibitory activity $\left(\mathrm{IC}_{50}: 0.29 \mu \mathrm{M}\right)$. This magnitude of improvement is consistent with that observed in the 6unsunstituted biaryl aminothiazine series previously reported. ${ }^{12}$

Our next library synthesis was aimed at enhancing potency, reducing lipophilicity ( $\log P$ : 3.6 for 8 versus 2.9 for 1 ), and improving ligand efficiency (LE: $0.29 \mathrm{kcal} \cdot \mathrm{mol}^{-1}$ for 8 versus 0.37 $\mathrm{kcal} \cdot \mathrm{mol}^{-1}$ for $\left.\mathbf{1}\right)$. Molecular modeling of 8 indicated the potential for hydrogen-bond interactions between the two methoxy groups and the flap backbone, and these interactions may be improved by moving the oxygen into the ring, i.e., forming a heterocyclic ring system. Replacement of dimethoxyphenyl with an appropriate heterocycle was also anticipated to reduce lipophilicity and improve ligand efficiency. Thus, threecomponent reactions of vinyl heterocycles with 3-(pyrimidin-5yl)-benzaldehyde (4a) were carried out, and this exercise led to 6-(3,5-dimethylisoxazol-4-yl) substituted trans aminothiazine ( \pm )-9 with moderate activity ( $\mathrm{IC}_{50}: 0.23 \mu \mathrm{M}$, Figure 3$)$. Again,
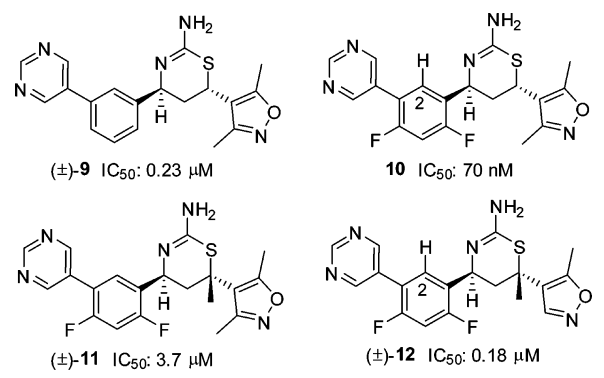

Figure 3. Structures of $( \pm)-9,10,( \pm)-11$, and $( \pm)-12$.

we introduced the difluoro substituents, and the resulting $(4 S, 6 S)$ enantiomer 10 exhibited activity 5-fold more potent than the lead compound $\mathbf{1}$. As compared to the dimethoxyphenyl analogue 8, compound 10 also showed reduced lipophilicity ( $\log P: 2.9$ versus 3.6 for 8 ) and improved ligand efficiency (LE: $0.35 \mathrm{kcal} \cdot \mathrm{mol}^{-1}$ versus $0.29 \mathrm{kcal} \cdot \mathrm{mol}^{-1}$ for 8$)$. As observed in other pairs of enantiomers, the opposite enantiomer of $\mathbf{1 0}$ was significantly less active (data not shown). Introduction of a quaternary methyl at C-6 in ( \pm )-11 dramatically reduced activity, while the activity was restored upon removal of the C-3 methyl of the isoxazole in $( \pm)-12$ (vide infra).

To better understand the binding conformation of the dimethylisoxazole group, we obtained a cocrystal structure of thiazine 10 bound in the BACE1 active site (Figure 4). ${ }^{15}$ As expected, the aminothiazine functionality formed intricate hydrogen-bond donor-acceptor interactions with aspartates 32 and 228 at the BACE1 active site; the C-2 hydrogen (see 10 in Figure 3) attached to the difluorophenyl ring formed a potential C-H hydrogen-bond with the backbone carbonyl of glycine 230; and the pyrimidine ring was projected into the opening of S3 pocket where it interacted with the carbonyl of serine 229 via a bridging water molecule. The two heteroatoms of the isoxazole ring served as hydrogen-bond acceptors to the amide $\mathrm{NH}$ groups of the threonine 72 and glutamine 73 located on the flap 


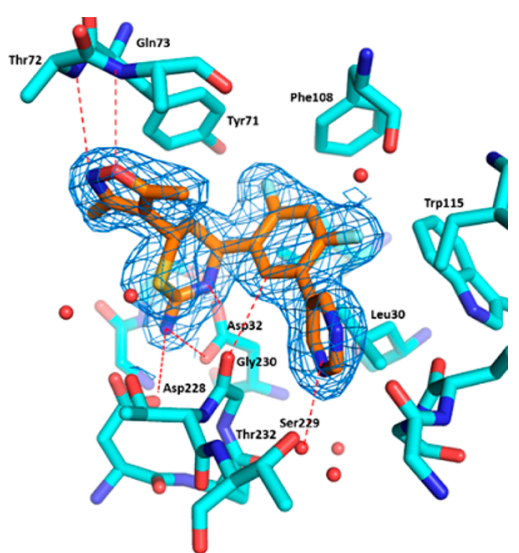

Figure 4. Cocrystal structure of 10 bound with BACE1 active site, with electron density contoured around $\mathbf{1 0}$ in blue mesh. ${ }^{15}$

backbone. ${ }^{16}$ The C-6 isoxazole ring was arranged nearly perpendicularly to the thiazine ring, and introduction of a quaternary methyl at C-6 as in compound $\mathbf{1 1}$ would cause severe steric repulsion between the two methyl groups (Figure 5). As a

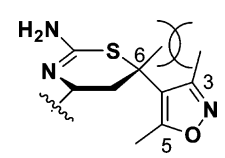

Figure 5. Steric interaction of the C-6 methyl of the thiazine ring with the C-3 methyl of isoxazole in $\mathbf{1 1}$.

result, the orthogonal arrangement would be unfavorable, thus resulting in diminished activity $\left(( \pm)-11 \mathrm{IC}_{50}: 3.7 \mu \mathrm{M}\right)$. However, when the C-3 methyl of the isoxazole was removed, as in compound 12, activity was restored. Indeed, the active enantiomer of compound ( \pm )-12 was estimated to have an $\mathrm{IC}_{50}$ value of $90 \mathrm{nM}$ (only one enantiomer was active based on SAR), comparable to that obtained with compound 10 ( $\mathrm{IC}_{50}: 70$ $\mathrm{nM}$, Figure 3).

With the C-4 des-methyl thiazine 10 identified as a moderately potent BACE1 inhibitor, our next step was to prepare the C-4 methyl-substituted aminothiazine 18 (Scheme 3). Reaction of amino alcohol $\mathbf{1 3}$, readily available using methodology recently developed in our laboratory, ${ }^{17}$ with benzoyl isothiocyanate provided the benzoyl thiourea derivative 14. Treatment of 14 with hydrochloric acid at $100{ }^{\circ} \mathrm{C}$ brought about ring closure and subsequent hydrolysis of the benzoyl group to give the 4,6-transaminothiazine 15, which was converted to its $\mathrm{NHBoc}$ derivative 16. The relative and absolute stereochemistry of $\mathbf{1 6}$ were confirmed by single crystal X-ray crystallography (Scheme 3$)^{18}$ Sukuki coupling of $\mathbf{1 6}$ with pyrimidin-5-yl-boronic acid and subsequent N-Boc deprotection furnished 18.

Compound $18\left(\mathrm{IC}_{50}: 8 \mathrm{nM}\right)$ was nearly 10 -fold more potent than the 4-des-methyl analogue 10. A similar trend was also observed in the iminopyrimidinone BACE1 inhibitors. ${ }^{19}$ Again, we obtained a cocrystal structure of $\mathbf{1 8}$ in the BACE1 active site, $^{20}$ and Figure 6 shows the overlay of cocrystal structures of both 10 and 18. The biaryl group in both inhibitors is oriented in a pseudoaxial conformation to occupy the contiguous S1-S3 hydrophobic pockets. A similar effect was seen in the related iminopyrimidinone analogue; ${ }^{19}$ however, we believe the underlying energetics are different. In the iminopyrimidinone case, the pseudoequatorial conformation was preferred by $1.4 \mathrm{kcal} / \mathrm{mol}$ with a C-4 hydrogen substituent; addition of the C-4 methyl
Scheme 3. Synthesis of Aminothiazine $18^{a}$

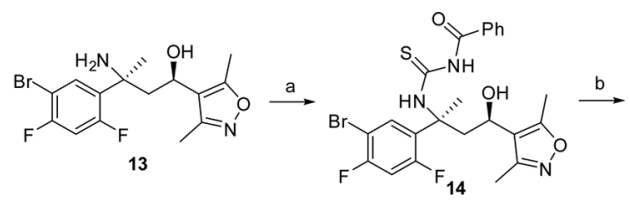

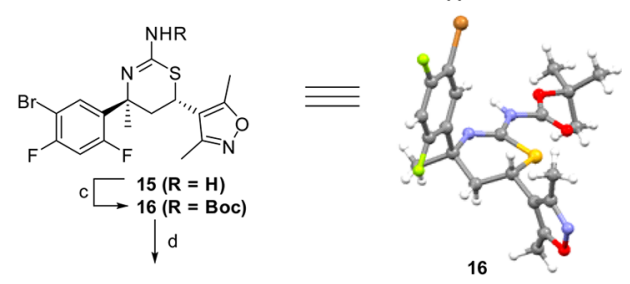

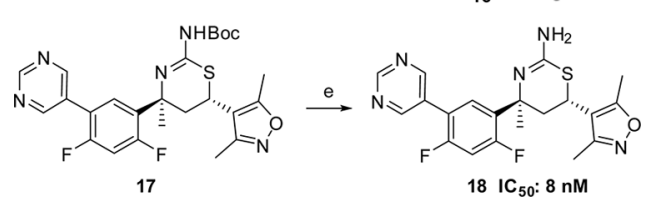

${ }^{a}$ Reagents and conditions: (a) benzoyl isothiocyanate, $\mathrm{CH}_{2} \mathrm{Cl}_{2}$, rt, 94\%; (b) $6 \mathrm{~N} \mathrm{HCl}$, dioxane, $100{ }^{\circ} \mathrm{C}, 6 \mathrm{~h}, 49 \%$; (c) $\mathrm{Boc}_{2} \mathrm{O}$, saturated $\mathrm{NaHCO}_{3}$, 1,4-dioxane, water, rt, 75\%; (d) pyrimidin-5-yl-boronic acid, $\mathrm{PdCl}_{2}\left(\mathrm{PPh}_{3}\right)_{2}, \mathrm{Cs}_{2} \mathrm{CO}_{3}$, DME, EtOH, $\mathrm{H}_{2} \mathrm{O}, 100{ }^{\circ} \mathrm{C}, 5 \mathrm{~min}, 60 \%$; (e) TFA, $\mathrm{CH}_{2} \mathrm{Cl}_{2}$, rt, $100 \%$. The thermal ellipsoid plot (50\% ellipsoids) of 16 is also shown above.

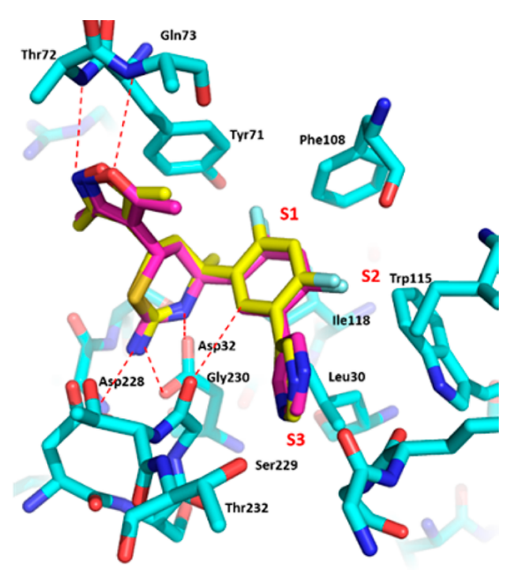

Figure 6. Overlay of cocrystal structures of 10 (violet) and 18 (yellow) bound with BACE1 active site.

group led to a loss of this energy barrier to access the preferred pseudoaxial conformation (Figure 7). In the case of compounds 10 and 18, quantum mechanical calculations at the $\mathrm{HF} / 6-31+\mathrm{G}^{*}$ level of theory showed that both compounds highly preferred the bound pseudoaxial conformations, by $10.2 \mathrm{kcal} / \mathrm{mol}$ for 10 and $5.3 \mathrm{kcal} / \mathrm{mol}$ for $\mathbf{1 8}$. We conclude that the 4-methyl group of $\mathbf{1 8}$

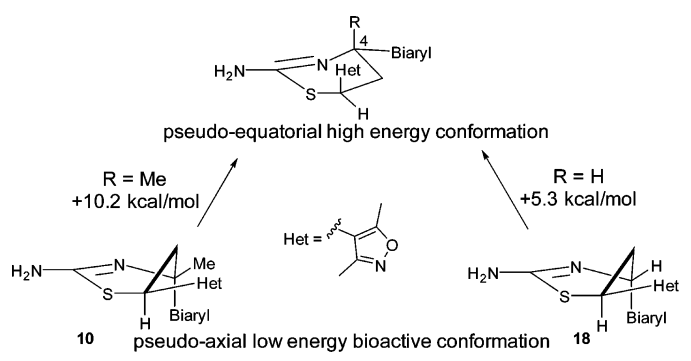

Figure 7. Energy difference between pseudoaxial and pseudoequatorial conformations of $\mathbf{1 0}$ and $\mathbf{1 8}$ 
contributes to activity primarily through a favorable hydrophobic interaction with isoleucine 118 , which lines the active site instead of conformational preference as shown in the iminopyrimidinone analogues.

Despite its potent activity, compound $\mathbf{1 8}$ demonstrated only modest reduction in brain $\mathrm{A} \beta$ peptides in rodents relative to the vehicle treated controls even at $30 \mathrm{mg} / \mathrm{kg} \mathrm{po}$, a result of moderate brain penetration. The exposure was limited by poor metabolic stability across species: only $23 \%$ (human), $49 \%$ (rat), and $48 \%$ (mouse) remained after a $10 \mathrm{~min}$ incubation with liver microsomes at $0.5 \mu \mathrm{M}$. The major metabolites resulted from oxidation of the pyrimidine ring, a pathway difficult to address because BACE1 inhibitory activity was sensitive to substitution of this ring. In the end, we were unable to improve metabolic stability while maintaining potent BACE1 inhibitory activity.

While our work to increase the potency of biaryl aminothiazines was being undertaken, workers at Eli Lilly also disclosed the discovery of furo $[3,4-d][1,3]$ thiazin-2-amine picolinamide 19 (LY2886721) (Figure 8), a potent BACE1 inhibitor that

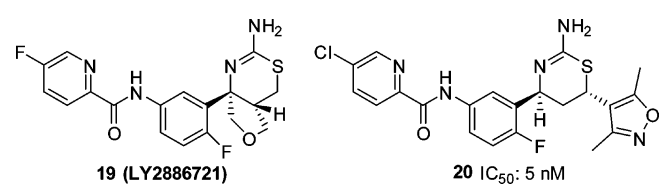

Figure 8. Structures of 19 (LY2886721) and 20.

reached phase II clinical trials in mild cognitive impairment. ${ }^{21,22}$ This new disclosure from Eli Lilly prompted us to replace the pyrimidyl moiety of $\mathbf{1 8}$ with a picolinamide. To test this approach, we prepared the 4-des-methyl aminothiazine 20 using the three-component, one-pot reaction of 5-chloro- $\mathrm{N}$-(4-fluoro3-formylphenyl)picolinamide, 3,5-dimethyl-4-vinylisoxazole and thiourea (scheme not shown). Compound 20 displayed good BACE1 inhibitory activity $\left(\mathrm{IC}_{50}: 5 \mathrm{nM}\right)$. As the C-4 quaternary methyl of the thiazine ring and the C-4 fluoro substituent of the phenyl ring generally contributed to the activity of the biaryl aminothiazine BACE1 inhibitors, we prepared picolinamide 22 from bromide 16 in four steps: palladium-catalyzed azidation, reduction of azide to aniline 21, amidation of the aniline, and removal of the $\mathrm{N}$-Boc group (Scheme 4). Interestingly,

Scheme 4. Synthesis of Aminothiazine $24^{a}$

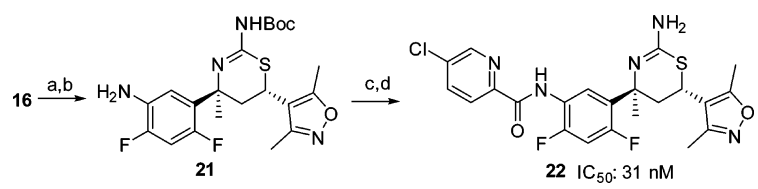

${ }^{a}$ Reagents and conditions: (a) $\mathrm{NaN}_{3}, \mathrm{CuSO}_{4} \cdot 5 \mathrm{H}_{2} \mathrm{O}$, L-ascorbic acid sodium salt, trans-1,2-(bismethylamino)cyclohexane, $80{ }^{\circ} \mathrm{C}$; (b) $\mathrm{Pd} / \mathrm{C}$ (10\%), $\mathrm{MeOH}, \mathrm{H}_{2}$ balloon, rt, $37 \%$ for two steps; (c) 5-chloropicolinic acid, HATU, Hunig's base, $\mathrm{CH}_{2} \mathrm{Cl}_{2}$, rt, $80 \%$; (d) TFA, $61 \%$

compound 22 was 6-fold less active than the 4-desmethyl analogue 20. The docking conformation of $\mathbf{2 2}$ (Figure 9) in the BACE1 active site indicated that the $\mathrm{NH}$ of the amide formed a hydrogen-bond with the backbone carbonyl of Gly230. The electronic repulsion between the 2-fluorine substituent on the phenyl and the amide carbonyl resulted in a nonoptimal hydrogen-bond configuration for the backbone carbonyl of Gly230. Relocation of fluoro substituent from C-4 to C-5 of the phenyl was expected to minimize this electronic repulsion.

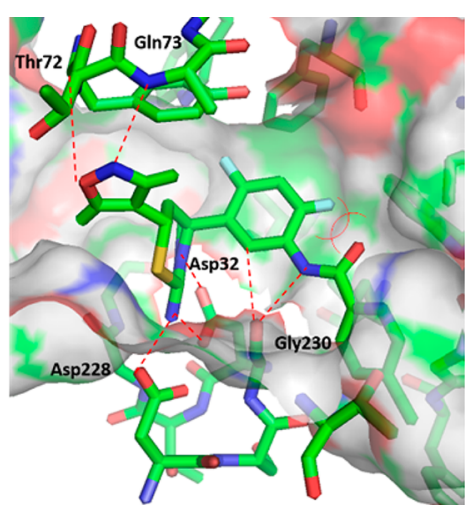

Figure 9. Docking conformation of $\mathbf{2 2}$ bound in the BACE1 active site.

Indeed, the 5,6-difluorophenyl analogue 23 was 44-fold more potent than 22 with an $\mathrm{IC}_{50}$ value of less than $1 \mathrm{nM}$. The superior activity of the 5,6-difluorophenyl picolinamides over their 4,6difluorophenyl counterparts appeared to be general, but the magnitude of the enhancement depended on the substituent(s) of the picolinic acid moiety. The 5,6-difluorophenyl picolinamides displayed either comparable or slightly improved activity over the 5-fluorophenyl analogues (data not shown). As we had expected, fluoro substitution at C-2 of the phenyl ring was not well tolerated $\left(25, \mathrm{IC}_{50}: 160 \mathrm{nM}\right)$ as this eradicated a potential $\mathrm{C}-\mathrm{H}$ hydrogen-bond between the $\mathrm{C}-2$ hydrogen of the phenyl and the carbonyl of Gly230 in the BACE1 backbone, as shown in the cocrystal structure of biaryl aminothiazine 10 (Figure 4). Overall, given a specific picolinamide, the activity of the analogues can be arranged in the order of 5,6-difluorophenyl (23) $\geq$ 5-fluorophenyl (24) > 4,6-difluorophenyl (22) > 2fluorophenyl (25).

The fluoro substituents exerted a profound impact not only on BACE1 inhibitory activity of the aminothiazine picolinamides, but also on their metabolic stability (Figure 10). For example, C-

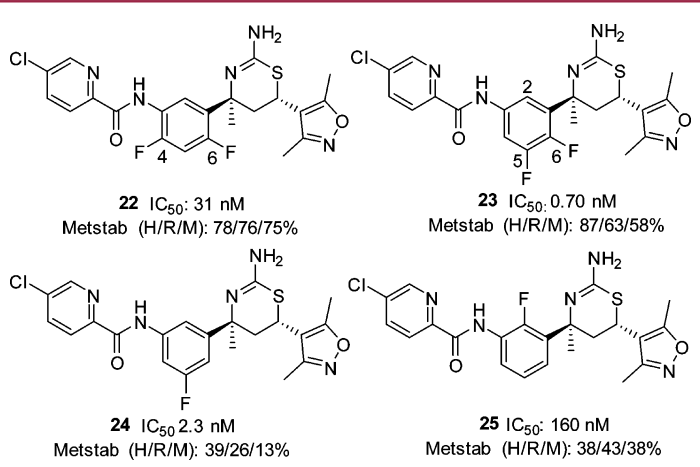

Figure 10. Metstab $(\mathrm{H} / \mathrm{R} / \mathrm{M})$ : \% percent compound that remained after a $10 \mathrm{~min}$ incubation with $(\mathrm{H})$ uman, $(\mathrm{R})$ at, or $(\mathrm{M})$ ouse liver microsomes at $0.5 \mu \mathrm{M}$.

2 fluoro substitution (25) was detrimental to both activity and metabolic stability. Our structure-metabolic stability relationship studies revealed the following order of metabolic stability: 5,6-difluorophenyl (23), 4,6-difluorophenyl (22) > 2-fluorophenyl (25), 5-fluorophenyl (24). Taken together, we concluded that the 5,6-difluorophenyl picolinamides provided the optimal balance between BACE1 inhibitory activity and metabolic stability. Accordingly, we focused on 5,6-difluorophenyl based carboxamides. Optimization of the amide side chain in the S3 pocket culminated in the discovery of pyrazine-carboxamide 26 
(Scheme 5) as a potent BACE1 inhibitor $\left(\mathrm{IC}_{50}: 0.9 \mathrm{nM}\right)$ with a good metabolic stability profile. Compound 26 was prepared

\section{Scheme 5. Synthesis of Aminothiazine $26^{a}$}

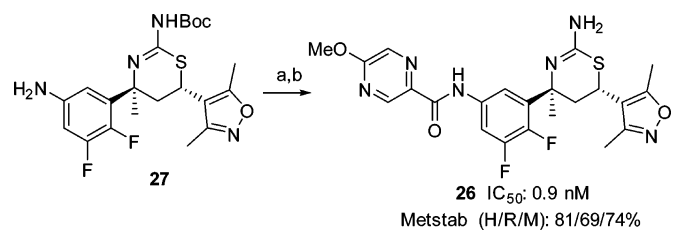

${ }^{a}$ Reagents and conditions: (a) 5-methoxypyrazine-2-carboxylic acid, HATU, Hunig's base, $\mathrm{CH}_{2} \mathrm{Cl}_{2}$; (b) TFA, $\mathrm{CH}_{2} \mathrm{Cl}_{2}, 63 \%$ for two steps.

from aniline 27 , which was available following the exact sequence described for compound 21 (Scheme 4).

Compound 26 demonstrated robust brain $\mathrm{A} \beta$ reduction in rodents. A single oral administration of 26 at $10 \mathrm{mg} / \mathrm{kg}$ in mice resulted in a reduction of brain $\mathrm{A} \beta 42$ peptide relative to vehicletreated control by $85 \%$ (data not shown). In rat studies, this compound demonstrated a dose-dependent reduction of brain $\mathrm{A} \beta 40, \mathrm{~A} \beta 42$, and total $\mathrm{A} \beta\left(\mathrm{A} \beta_{1-x}\right)$ when dosed orally (Figure 11$)$.

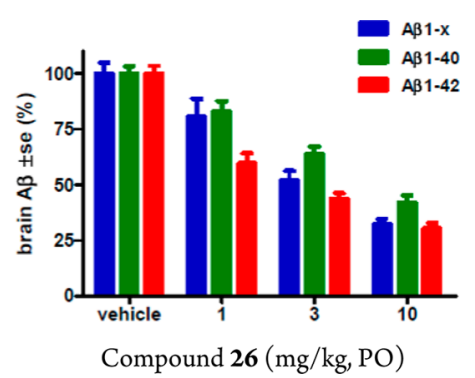

Figure 11. Dose-dependent inhibition of $\mathrm{A} \beta 40, \mathrm{~A} \beta 42$, and total $\mathrm{A} \beta$ $\left(\mathrm{A} \beta_{1-x}\right)$ in rat brain by 28 at $5 \mathrm{~h}$ after oral administration $(n=5$ rats).

The exposure of $\mathbf{2 6}$ was also measured in rat plasma and brain samples (Table 1) to allow quantification of the PK/PD

Table 1. Brain, Plasma Concentration, and Brain/Plasma Ratio of $26^{a}$

$\begin{array}{cccc}\begin{array}{c}\text { dose } \\ (\mathrm{mg} / \mathrm{kg})\end{array} & \begin{array}{c}\text { plasma conc }(\mathrm{nM}) \\ (\mathrm{SD})\end{array} & \begin{array}{c}\text { brain conc }(\mathrm{nM}) \\ (\mathrm{SD})\end{array} & \begin{array}{c}\text { brain/ } \\ \text { plasma }\end{array} \\ 1 & 150(65) & 67(46) & 0.44(0.14) \\ 3 & 360(75) & 160(30) & 0.46(0.10) \\ 10 & 1500(320) & 420(190) & 0.30(0.10)\end{array}$

${ }^{a}$ Compound dosed PO to female rats in PEG-400/EtOH/Tween 80 (84:15:1); plasma and brain collected $5 \mathrm{~h}$ postdose ( 5 rats/dose) for determination of exposure and brain $\mathrm{A} \beta$ levels. Data are mean values $(n=5)$ with SD in parentheses.

relationship (Figure 12). Analysis of the rat brain $\mathrm{A} \beta 42$ reduction versus the total plasma concentration curve (Figure 12) resulted in the estimation of a brain $\mathrm{A} \beta 42 \mathrm{EC}_{50}$ of $260 \mathrm{nM}$ total plasma concentration or $13 \mathrm{nM}$ free drug plasma level (using rat plasma protein binding data for $28,95 \%$ ), which is 14 -fold the cellular $\mathrm{IC}_{50}$ value of the compound. In terms of brain exposure required for efficacy, $260 \mathrm{nM}$ total plasma exposure was achieved close to the $3 \mathrm{mg} / \mathrm{kg}$ drug dose (Table 1), which gave $360 \mathrm{nM}$ plasma and $160 \mathrm{nM}$ total brain exposure. Therefore, the total brain exposure at the $\mathrm{ED}_{50}$ was near $160 \mathrm{nM}$. Comparing this value to the cell

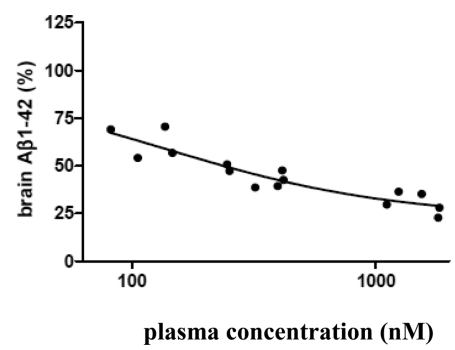

Figure 12. Brain $A \beta 42$ reduction and plasma concentration curve of 26.

$\mathrm{IC}_{50}(1 \mathrm{nM})$ implied significant brain drug binding for compound 26.

Compound 26 showed an $\mathrm{IC}_{50}$ of $0.64 \mu \mathrm{M}$ in the hERG wholecell patch clamp assay, which provided a 49-fold separation versus the brain $\mathrm{A} \beta 42 \mathrm{EC}_{50}$ of $13 \mathrm{nM}$ free drug level in plasma. More studies would be required to determine if $\mathrm{hERG}$ inhibition is a potential safety issue for this compound.

The pyrazine-carboxamide $\mathbf{2 6}$ contains an amide bond, which could potentially be hydrolyzed in vivo to release the free aniline 28 (Figure 13). Indeed, in the mouse $\mathrm{A} \beta$ reduction studies,

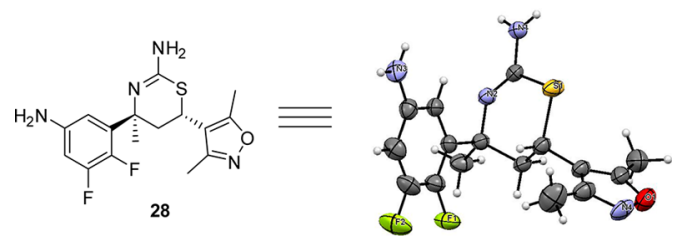

Figure 13. Thermal ellipsoid plot (50\% ellipsoids) of aniline 28 .

aniline 28 was detected in the plasma $3 \mathrm{~h}$ after oral administration. Free anilines per se are not inherently mutagenic, but further metabolism generates species that could be mutagenic. To address this concern, we submitted $\mathbf{2 8}$ to the standard Ames test, in which it was determined to be nonmutagenic. Compound $\mathbf{2 8}$ was obtained from 27 (Scheme 5 ) via removal of the $N$-Boc group. The absolute configuration of 28 was confirmed by way of single-crystal X-ray diffraction analysis (Figure 13). ${ }^{23}$

The cytochrome P450 inhibitory potential of compound 26 was also determined using recombinant CYP1A2, CYP2C9, CYP2C19, CYP2D6, and CYP3A4 in order to assess the potential likelihood of drug-drug interactions. Low levels of inhibition were observed at all major human P450 isozymes $\left(\mathrm{IC}_{50}>20 \mu \mathrm{M}\right)$ with the highest level of inhibition against CYP2C8 ( IC $\left._{50:} 5 \mu \mathrm{M}\right)$.

In summary, we recognized certain features in $\mathbf{1}$ and used them to develop a general approach to enhance its potency by targeting the flap backbone in the active site of BACE1. This approach led to dimethoxyphenyl at C- 6 of the thiazine ring as an initial binder, which incorporated weak hydrogen-bond acceptors to the flap backbone. The interactions with the flap were optimized with the dimethylisoxazole heterocycle. The quaternary methyl substituent at C-4 was introduced, and the resulting aminothiazine $\mathbf{1 8}$ was 34 -fold more potent than $\mathbf{1}$. We then replaced the pyrimidyl moiety with a carboxamide, and our SAR studies showed that the 5,6-difluorophenyl moiety in the $S 1$ pocket was optimal in terms of activity and metabolic stability. Optimization of the amide side chain in the S3 pocket culminated in the discovery of the pyrazine-carboxamide 26 as a potent BACE1 inhibitor with good metabolic stability. This compound demonstrated robust brain A $\beta$ lowering after oral dosing in rat dose-response studies. 
Taken together, we believe that compound $\mathbf{2 6}$ can be considered for further preclinical evaluations for testing the amyloid cascade hypothesis.

\section{ASSOCIATED CONTENT}

\section{S Supporting Information}

The Supporting Information is available free of charge on the ACS Publications website at DOI: 10.1021/acsmedchemlett.5b00432.

Synthetic methods and characterization data for compounds 6-28 and methods for in vitro, in vivo, and pharmacokinetic assays (PDF)

\section{AUTHOR INFORMATION}

\section{Corresponding Author}

*Tel: 203-677-7485. E-mail: yong-jin.wu@bms.com.

\section{Notes}

The authors declare no competing financial interest.

\section{ACKNOWLEDGMENTS}

We thank Dr. Nicholas Meanwell for critically reviewing this manuscript. We also thank Rudy Krause, Alan Xu Lin, and Tracey Hall for various biological evaluations, and A. Arumugam, K. Mahammed, Murali Botlagunta, P. N. Arunachalam, Arun Kumar Gupta, and Richard Rampulla for scaling up intermediate $\mathbf{1 5 .}$

\section{ABBREVIATIONS USED}

TFA, trifluoroacetic acid; TEA, triethylamine; DMF, N,Ndimethylformamide; HATU, 1-[bis(dimethylamino)methylene]-1H-1,2,3-triazolo[4,5-b]pyridinium 3-oxid hexafluorophosphate; rt, room temperature; Metstab, metabolic stability; CYP, cytochrome P450 enzymes; po, oral administration; $\mathrm{PK} / \mathrm{PD}$, pharmacokinetic/pharmacodynamic

\section{REFERENCES}

(1) Koh, J.-Y.; Yang, L.-L.; Cotman, C. W. Beta-amyloid protein increases the vulnerability of cultured cortical neurons to excitotoxic damage. Brain Res. 1990, 533, 315-320.

(2) Haass, C.; Selkoe, D. J. Soluble protein oligomers in neurodegeneration: lessons from the Alzheimer's amyloid $\beta$-peptide. Nat. Rev. Mol. Cell Biol. 2007, 8, 101-112.

(3) Vassar, R.; Kuhn, P. H.; Haass, C.; Kennedy, M. E.; Rajendran, L.; Wong, P. C.; Lichtenthaler, S. F. Function, therapeutic potential and cell biology of BACE proteases: current status and future prospects. J. Neurochem. 2014, 130, 4-28.

(4) Schellenberg, G. D.; Montine, T. J. The Genetics and Neuropathology of Alzheimer's Disease. Acta Neuropathol. 2012, 124, 305-323.

(5) Jonsson, T.; Atwal, J. K.; Steinberg, S.; Snaedal, J.; Jonsson, P. V.; Bjornsson, S.; Stefansson, H.; Sulem, P.; Gudbjartsson, D.; Maloney, J.; Hoyte, K.; Gustafson, A.; Liu, Y.; Lu, Y.; Bhangale, T.; Graham, R. R.; Huttenlocher, J.; Bjornsdottir, G.; Andreassen, O. A.; Jonsson, E. G.; Palotie, A.; Behrens, T. W.; Magnusson, O. T.; Kong, A.; Thorsteinsdottir, U.; Watts, R. J.; Stefansson, K. A. A mutation in APP protects against Alzheimer's disease and age-related cognitive decline. Nature 2012, 488, 96-99.

(6) larson, M. E.; Lesne, S. E. Soluble A $\beta$ oligomer production and toxicity. J. Neurochem. 2012, 120 (suppl. 1), 125-139.

(7) De Strooper, B.; Vassar, R.; Golde, T. The secretases: enzymes with therapeutic potential in Alzheimer disease. Nat. Rev. Neurol. 2010, 6, 99-107.

(8) Stamford, A.; Strickland, C. Inhibitors of BACE for treating Alzheimer's disease: a fragment-based drug discovery story. Curr. Opin. Chem. Biol. 2013, 17, 320-8.
(9) Yan, R; Vassar, R. Targeting the $\beta$ secretase BACE1 for Alzheimer's disease therapy. Lancet Neurol. 2014, 13, 319.

(10) Oehlrich, D.; Prokopcova, H.; Gijsen, H. J. M. The evolution of amidine-based brain penetrant BACE1 inhibitors. Bioorg. Med. Chem. Lett. 2014, 24, 2033-45.

(11) Audia, J. E.; Mergott, D. J.; Dustin, J.; Sheehan, S. M.; Watson, B. M. Aminodihydrothiazine derivatives as BACE inhibitors for the treatment of Alzheimer's diseases. WO-2009/134617.

(12) May, P. C.; Dean, R. A.; Lowe, S. L.; Martenyi, F.; Sheehan, S. M.; Boggs, L. N.; Monk, S. A.; Mathes, B. M.; Mergott, D. J.; Watson, B. M.; Stout, S. L.; Timm, D. E.; LaBell, E. S.; Gonzales, C. R.; Nakano, M.; Jhee, S. S.; Yen, M.; Ereshefsky, L.; Lindstrom, T. D.; Calligaro, D. O.; Cocke, P. J.; Hall, D. G.; Friedrich, S.; Citron, M.; Audia, J. E. Robust central reduction of amyloid- $\beta$ in humans with an orally available, nonpeptidic $\beta$-secretase inhibitor. J. Neurosci. 2011, 31, 16507-16516.

(13) Zhu, Y.; Huang, S.; Wan, J.; Yan, L.; Pan, Y.; Wu, A. Two novel diastereoselective three-component reactions of alkenes or 3,4-dihydro$(2 \mathrm{H})$-pyran with urea/thiourea-aldehyde mixtures: $[4+2]$ cycloaddition vsbBiginelli-type reaction. Org. Lett. 2006, 8, 2599-2602.

(14) After this work was near completion, Lilly disclosed LY2811376 in ref 12 by the end of 2011. This paper suggests that the purpose of the quaternary methyl group is to exacerbate the desired topology and enhance chemical stability, but no details were provided.

(15) Structure coordinates have been deposited with the RSCB Protein Data Bank (PDB ID 5ENM).

(16) For an example of applying hydrogen-bond interactions involving 3,5-dimethylisoxazole in drug discovery, see: Hewings, D. S.; Wang, M.; Philpott, M.; Fedorov, O.; Uttarkar, S.; Panagis Filippakopoulos, P.; Picaud, S.; Vuppusetty, C.; Marsden, B.; Knapp, S.; Conway, S. J.; Heightman, T. D. 3,5-Dimethylisoxazoles act as acetyl-lysine-mimetic bromodomain ligands. J. Med. Chem. 2011, 54, 6761-70.

(17) Guernon, J.; Marcin, L.; Higgins, M.; Yang, F.; Shi, J.; Snyder, L.; Thompson, L. A.; Wu, Y.-J. Synthesis of $\beta$-disubstituted $\beta$-amino isoxazolyl ketones by addition of ketimines with isoxazolyl methyl ketone enolates. Tetrahedron Lett. 2014, 55, 2134-2137.

(18) The crystal structure of $\mathbf{1 6}$ has been deposited in the Cambridge Crystallographic Data Centre (CCDC \#: 1436245).

(19) Edwards, P. D.; Albert, J. S.; Sylvester, M.; Aharony, D.; Andisik, D.; Callaghan, O.; Campbell, J. B.; Carr, R. A.; Chessari, G.; Congreve, M.; Frederickson, M.; Folmer, R.H. A.; Geschwindner, S.; Koether, G.; Kolmodin, K.; Krumrine, J.; Mauger, R. C.; Murray, C. W.; Olsson, L.; Patel, S.; Spear, N.; Tian, G. Application of fragment-based lead generation to the discovery of novel, cyclic amidine $\beta$-secretase inhibitors with nanomolar potency, cellular activity, and high ligand efficiency. J. Med. Chem. 2007, 50, 5912-5925.

(20) Structure coordinates have been deposited with the RSCB Protein Data Bank (PDB ID 5ENK).

(21) May, P. C.; Willis, B. A.; Lowe, S. L.; Dean, R. A.; Monk, S. A.; Cocke, P. J.; Audia, J. E.; Boggs, L. N.; Borders, A. R.; Brier, R. A.; Calligaro, D. O.; Day, T. A.; Ereshefsky, L.; Erickson, J. A.; Gevorkyan, H.; Gonzales, C. R.; James, D. E.; Jhee, S. S.; Komjathy, S. F.; Li, L.; Lindstrom, T. D.; Mathes, B. M.; Martènyi, F.; Sheehan, S. M.; Stout, S. L.; Timm, D. E.; Vaught, G. M.; Watson, B. M.; Winneroski, L. L.; Yang, Z.; Mergott, D. J. The potent BACE1 inhibitor LY2886721 elicits robust central $\mathrm{A} \beta$ pharmacodynamic responses in mice, dogs, and humans. J. Neurosci. 2015, 35, 1199-1200.

(22) Audia, J. E.; Mergott, D. J.; Shi, C. E.; Vaught, G. M.; Watson, B. M.; Winneroski, L. L., Jr. BACE inhibitors. WO-2011/005738.

(23) The crystal structure of $\mathbf{2 9}$ has been deposited in the Cambridge Crystallographic Data Centre (CCDC \#: 1436246). 